\title{
The Legendary Creativity of Hayao Miyazaki and Shigeru Miyamoto as a Product of Metacognitive Awareness, Family, and Environment
}

\author{
Mike McClelland \\ University of Georgia
}

\begin{abstract}
This article compares two eminent programmers, Shigeru Miyamoto and Hayao Miyazaki, and their respective works, the video game The Legend of Zelda: The Ocarina of Time and the film Princess Mononoke. It discusses their creativity in the context of their above-average access and opportunity to metacognitive skill development, ideation, production, and influence in relation to methods recommended in the research on creativity and genius. This article also looks at how their individual creativity was nurtured by family and scholarship, influenced by birth order and parental relationships, and enhanced by their geographic location and work place. The article concludes that all of these factors combined to allow Miyamoto and Miyazaki to reach legendary levels of creativity, with remarkable similarity to one another.
\end{abstract}

Keywords: Creativity, Metacognition, Gaming, Anime, Japan 
Shigeru Miyamoto, Nintendo's current coRepresentative Director and the creator of many of the most memorable video games of all time and Hayao Miyazaki, co-founder of famed film animation studio Studio Ghibli, are two of the world's leading creative talents, internationally famous in their fields and superstars in their native Japan. What led these two men, born 11 years and 400 miles apart, to their legendary creative genius? Did their awareness of their own creativity lead to its growth? Was it innate or were they shaped by their upbringings, their schooling, or their surroundings? Does the fact that they are both from Japan play a factor in their shared ability to unlock the delight of childhood? While asking such questions inevitably lends itself to wild speculation, it is indisputable that these two men are seen as creative geniuses both in terms of their entire careers and a great number of specific projects. For the purposes of this article, Miyamoto's The Legend of Zelda: The Ocarina of Time and Miyazaki's Princess Mononoke will be considered specifically. Coincidentally, these two projects were released just over one year apart from each other. In examining their entire careers in broad terms and these two projects in specific, it is likely that whatever innate creativity Miyamoto and Miyazaki were born with grew because of their active engagement in metacognitive skill development as discussed by Hargrove (2013), was mechanized because they metacognitively moderated their creative ideation and production in the style described by Puryear (2015), was assisted by metacognitive cultural intelligence in the way described by Yunlu, Clapp-Smith, \& Shaffer (2017), was nurtured in them in the style outlined by Michel \& Dudek (1991), was shaped by their birth order and parental relationships as described in Gute et al. (2008), was enhanced by their work environments in a examples that Stokols et al. (2002) would swoon over, and was magnified by the fact that they worked in the great creative cities (as defined by Florida (2003)) of Kyoto and Tokyo.

For the purposes of this article, the personal background of the creative achievements of both Miyamoto and Miyazaki will be presented in offensively but necessarily short summary, with a particular focus on the specific projects The Legend of Zelda: Ocarina of Time (Miyamoto) and Princess Mononoke (Miyazaki). The format of these summaries is similar for effect and for the demonstration of how closely they relate.

\section{Childhoods of Nurtured Creativity, Early Careers in Creative Cities, Late Careers of Creative Legend}

Born in Sonobe, Japan in 1952, Shigeru Miyamoto was the youngest of two children. The son of a traditional mother and friendly, English-teacher father, he spent his childhood days playing and exploring the forests and fields outside of his family home. His family was financially comfortable. According to a profile in The New Yorker, his creativity was encouraged by his parents, who also nurtured his interest in activities like manga drawing and gardening. He moved to Kyoto in 1976 after completing art school. At that time, Kyoto had a booming and growing student culture. Students gathered in cafés and spoke heatedly about art and politics (Nikai and Nishiyami, 2005). His relationship with video games began through a position as an apprentice at Nintendo in 1977. By 1980, he was the company's first artist, and was tasked with projects related to the company's new videogaming endeavors. His first game, Donkey Kong, was inspired by the popular cartoon Popeye. His success enabled him to spread his wings, and his interests directly influenced the legendary franchises he created, such as forest adventuring (Zelda), sibling cooperation (Super Mario Brothers), and even gardening (Pikmin).

In 1998, computer technology became advanced enough for Miyamoto to create what many consider to be his masterpiece (George, 2011), The Legend of Zelda: Ocarina of Time. Though it was the fifth game in the Legend of Zelda series, it represented Miyamoto's 
first chance to create large, three-dimensional worlds and puzzles. The game was a unanimous critical and commercial success upon its release, with audiences, critics, and scholars praising its creativity. It is widelyconsidered to be the best videogame of all time (Gilbert, 2017).

Born in Akebono-cho (a village within Tokyo's borders) in 1941, Hayao Miyazaki was the second of four sons. The son of a stern and intelligent mother and friendly, businessman father, he spent his childhood days escaping into books, particularly fantasies, because World War II had made things very frightening (Talbot, 2005). His family was very wealthy. According to McCarthy (2002) his creativity was encouraged by his parents, who also nurtured his interest in activities like reading, drawing (particularly manga), and aeronautics. He moved to Tokyo in 1963 to work at Toei Animation. Tokyo was, at the time, a hotbed of student life, rife with cultural shifts, business booms and protests. His relationship with animation began through a position with Toei, but his first film, The Castle of Cagliostro wasn't released until 1979 and was based on the Lupin III manga series. In 1985 he founded Studio Ghibli, which is now an iconic brand in Japan and around the world. The studio's success enabled him to spread his wings, and his interests directly influenced the legendary films he created, such as steampunk (Castle in the Sky), aeronautics (Porco Rosso, The Wind Rises), and lost childhood (Spirited Away, Howl's Moving Castle), a result of his own childhood being influenced by the war and by his mother's illness.

In 1997, technology became advanced enough for Miyazaki to create what many critics consider to be his masterpiece (IndieWire Staff, 2014), Princess Mononoke. Though he had long been an expert in animation, the advancement of CGI allowed Miyazaki to create the large scale and wild, natural movements of the mythical forest creatures he had imagined as a child. The film was released to unanimous critical and commercial success upon its release, with audiences, critics, and scholars. It is widely-considered to be one of the best animated films of all time, sitting alongside Miyazaki’s own Spirited Away.

\section{Literature Review}

The similarity between the two men's backgrounds and the crossover of themes in their work are impossible to ignore. Is this the formula for maximum creative success? From a metacognitive standpoint, one developmental asset that both men had was that they were both put into creative positions that required problem solving from the very beginning of their careers. Hargrove (2013), suggests that artists who begin analyzing their creativity in an academic environment may actually end up being stifled by it, explaining that cognition is "stifled by the rigid framework of many university design programs. Students are often told how to think about the design process, without explicit and purposeful instruction that allows for self-regulation of cognitive processes." (491-492). Though Miyamoto attended art school, both he and Miyazaki immediately thrown into professional environments where they were forced to not only explore their creativity but to experiment with it and eventually share it. In their early days at Nintendo and Toei Animation, respectively, both men were tasked with growing and understanding their own creative thinking in order to develop their employers' business interest. Hargrove (2013) explains that creative thinking "can be defined as a metacognitive process - of generating novel or useful associations that better solve a problem, produce a plan, or result in a pattern, structure, or product not clearly present before" (492). Because creativity was a skill that Miyamoto and Miyzaki had to develop, they had to understand their own creativity, and that understanding subsequently to engage in more complex and strategic creative endeavors. Both men were asked to take a metacognitive approach to their own skills, and as a result Miyamoto and Miyazaki actually became more creative in the process. 
Puryear (2015) further cements this idea with his Cognitive-Creative Sifting Model, which explains that ideas go through a cognitive "sifter" on their way to becoming finished thoughts or products. One conclusion that Puryear's study suggested was "that individuals in the higher percentiles for ideation may specifically benefit from training in metacognitive awareness. Incorporating cognitive interventions aimed at developing these skills may improve the efficacy of programs aimed at the creatively gifted" (Puryear, 2015, p. 340). Studies such as this that creative thinking is a muscle that is best exercised through metacognitive exertion, and in their very first professional positions both Miyamoto and Miyazaki were given the opportunity to engage in such endeavors.

Flavell (1979) subdivided metacognitive knowledge into three areas: knowledge of persons (either intrapersonal or interpersonal), knowledge of task, and knowledge of strategies (Flavell, 1979, p. 907). Pureyear (2015) interpreted this in the context of creativity, explaining that "in a cognitive-creative sifting framework, this relates to abilities in valuing potential creative options either to oneself or to others" (Puryear, 2015, p. 336). Because of the nature of their personalities, their positions, and the culture of their era and locations, Miyamoto and Miyazaki were both perfectly suited to approach creativity in ways that related to task, strategy, and other people. Because it was the nature of their respective businesses right from the beginning, they were immediately tasked with not only valuing and encouraging. creativity in themselves but also in those around them.

This ability to stoke creativity in both themselves and others was vital to each man's creative growth. Yunli, Clapp-Smith, \& Shaffer (2017) expand on this idea in connecting cultural intelligence (CQ) to individual creativity. CQ is defined as "a person's capability to adapt effectively to new cultural contexts" and is "a form of situated intelligence where intelligently adaptive behaviors are culturally bound to the values and beliefs of a given society or culture" (Earley \& Ang, 2003) and it comprises four dimensions: metacognitive, cognitive, motivational, and behavioral. In a study, Yunli, et. al., found that metacognitive, cognitive, and motivational CQ were positively associated with creativity. Miyamoto and Miyazaki's exploratory youth and necessitous-creative career beginnings fostered in them a high CQ, which further bolstered their already above-average creative development.

The striking similarities between these two men become even more evident when adding creative studies to the aforementioned metacognitive analysis. The sample size is far too low to say, but it is possible to see where Miyamoto and Miyazaki's backgrounds overlap with the theories and research of major scholars in the study of creativity. The first thing to acknowledge is that this strongly relates to the idea that the idea of what creativity is and can be comes from within the context of cultural (Glaveanu, 2010). The cultural context for both men - from home culture, to national culture, to Post-WWII culture, to manga culture they both loved - was eerily similar, and that similar culture led to similar creative sensibilities.

Their relationships with their mothers appears at a summary glance to be very much like the ones like Michel \& Dudek (1991) describe as ideal for creativity. And while their nurtured, creative childhoods suggests an environment antithetical to those described by Gebart-Eaglemont \& Foddy (1994), both men spent a great deal of time in isolation as youngsters. They were educated and began their professional careers in cities filled with the characteristics Florida (2003) describes as exemplary of a creative city. And as cherished second children whose natural abilities and affinities were nurtured from a young age, both Miyazaki and Miyamoto fit into Gute et al. (2008)'s assertions of the relationship between family and creativity. 


\section{Discussion}

What makes creativity legendary? For the purposes of this article, it is the simple fact that Miyamoto and Miyazaki's specific respective projects The Legend of Zelda: Ocarina of Time and Princess Mononoke are considered to be the very best products in two fields generally thought to require creativity. Videogames and animated films require both artistic and technological creativity to stay current in ever-changing fields, yet twenty years later both Ocarina and Mononoke are considered to be standard-bearers. The specificity of this argument ignores the pertinent fact that neither project was an anomaly. Both Miyamoto and Miyazaki are notable for the consistent quality of their output and both have multiple projects, even dozens, that compare in quality to their most famous works.

This genesis of this project came from a question of geography, whether the fact that two of the more prolific, prominent living creative minds came from the same region of the world. That question, of course, expanded the era in which they worked - particularly the era in which they began working - and then dove into the specifics of their lives. The most consistent point that came across in both their biographical information was that their creativity was consistently encouraged - by their families in a children and young adults, by their employers as junior employees, and by the coworkers and society at large as they grew into leaders in their fields. Even their locations in creative cities constantly encouraged them to reflect on and develop their creativity. This marries perfectly with both metacognitive and creativity studies, many of which emphasize the fact that creativity grows as it is used, developed, reflected upon, and experimented with.

\section{Conclusions and Future Study}

While Miyamoto and Miyazaki fit the creative standards laid out by an abundance of metacognitive and creativity research, there are also areas that beg for further exploration. While the work of Hargrove (2013), Pureyear (2015) , Flavell (1979), Yunli, Clapp-Smith, \& Shaffer (2017) was all discussed as it related to Miyamoto and Miyazaki's creativity, a vital next step would be conducting historical and ethnographic studies of Nintendo and Studio Ghibli through a metacognitive lens. Additionally, the individual success of both men pushes back against the thought that success in Eastern societies is groupbased, however the working methods of both and the "Westernization" (noting the problematic nature of the terms Eastern, Western, and Westernized) suggest that they do perhaps fit within the suggestions of Yao, et al. (2012) work in some ways. Further exploration, specifically with regards to the work of Kurtzburg \& Amabile (2001) and Florida (2002) and Florida (2003) would surely be a fruitful endeavor. Also, both Miyazaki and Miyamoto were nurtured by their parents, which goes against the findings of Gebart-Eaglemont \& Foddy (1994), but the fact that Miyamoto spent a great deal of time in isolation and Miyazaki spent a lot of time with a bedridden mother perhaps does suggest some overlap with their work.

Creativity can often seemlikeaparadox, simultaneously appearing to be entirely personal yet also universal, and never more is that paradox more evident than it is in the work of Shigeru Miyamoto and Hayao Miyazaki. Over the years, their creative work has been defined by their childhood experiences, their openminded visions of the world, their relationship to their cities of Kyoto and Tokyo and even, in ways, to the commonalities of regional experience. Their creative force has been particularly evident by the fact that best work was shaped not only by their imaginations, but by their ability to use the most current technology to compliment it. Finally, and perhaps most significantly, it appears that their metacognitive approach to their own creativity allowed them to not only nurture said creativity in themselves, but also in the people and cultures around them. 


\section{References}

Crozier, W. R. (2003). Individual Differences in Artistic Achievement: A Within-Family Case Study. Creativity Research Journal, 15:4, 311-319.

Earley, P. C., \& Ang, S. (2003). Cultural intelligence: Individual interactions across cultures. Palo Alto, CA: Stanford University Press.

Erbas, A. K., \& Bas, S. (2015). The Contribution of Personality Traits, Motivation, Academic RiskTaking and Metacognition to the Creative Ability in Mathematics. Creativity Research Journal, 27(4), 299-307.

Flavell, J. H. (1979). Metacognition and cognitive monitoring: A new area of cognitivedevelopmental theory. American Psychologist, 34, 906-911.

Florida, R. (2003). Cities and the creative class. City \& Community.

Florida, R. (2002). Rise of the creative class. Washington Monthly.

Gardner, K. G. \& Bull, K.S. (1991). Birth position, gender, siblings, and parental Occupations. Creativity Research Journal, 4:1, 88-90.

Gilbert, B. (2017). The 50 Best Games of All Time, According to Critics on Metacritic. Business Insider, March 2017.

Glaveanu, V.P. (2010). Creativity As Cultural Participation. Journal for the Theory of Social Behaviour, 44:1.

Gute, G., et al. (2008). The Early Lives of Highly Creative Persons: The Influence of the Complex Family, Creativity Research Journal, 20:4, 343357.

Gebart-Eaglemont, J.E., \& Foddy, M. (1994). Creative potential and the sociometric status of children. Creativity Research Journal, 7:1, 47-57.

Hargrove, R. (2013). Assessing the long-term impact of a metacognitive approach to creative skill development. International Journal of Technology \& Design Education, 23:3, 489-517.
Hargrove, R. A., \& Nietfeld, J. L. (2015). The Impact of Metacognitive Instruction on Creative Problem Solving. Journal Of Experimental Education, 83:3, 291-318.

Kurtzberg, T. R. \& Amabile, T. M. (2001). From Guilford to Creative Synergy: Opening the Black Box of Team-Level Creativity. Creativity Research Journal, 13, 285-294.

LeBoutillier, N., \& Barry, R. (2018). Psychological Mindedness, Personality and Creative Cognition. Creativity Research Journal, 30(1), 78-84.

Lynne J. Millward \& Helen Freeman (2002). Role Expectations as Constraints to Innovation: The Case of Female Managers. Creativity Research Journal, 14:1, 93-109.

Martin, L., \& Wilson, N. (2017). Defining Creativity with Discovery. Creativity Research Journal, 29(4), 417-425.

McCarthy, H. (2002). Hayao Miyazaki: Master of Japanese Animation. Berkeley, CA: Stone Bridge Press.

Michel, M. \& Dudek, S. Z. (1991). Mother-child relationships and creativity, Creativity Research Journal, 4:3, 281-286.

Nikai, A. \& and Nishiyami, M. (2005). Kyoto Cafes and Students in the 1970s. The Kyoto Project. Retrieved from http://www.thekyotoproject.com. Paumgarten, Nick (2010). Master of Play. The New Yorker, December 2010.

Puryear, J. S. (2015). Metacognition as a Moderator of Creative Ideation and Creative Production. Creativity Research Journal, 27(4), 334-341.

Rojas, J. P., \& Tyler, K. M. (2018). Measuring the Creative Process: A Psychometric Examination of Creative Ideation and Grit. Creativity Research Journal, 30(1), 29-40.

Runco, M. A. (2015). Meta-Creativity: Being Creative About Creativity. Creativity Research Journal, 27(3), 295-298.

Staff, The Playlist. From Worst To Best: Ranking The Films Of Hayao Miyazaki. IndieWire. IndieWire, 31 May 2017. 
Stokols, D., Clitheroe, \& Zmuidzinas. (2002). Qualities of Work Environments That Promote Perceived Support for Creativity. Creativity Research Journal.

Talbot, M. (2005). The Animated Life. The New Yorker, January 2015.
Yao, X., et al. (2012). The Role of IndividualismCollectivism in the Individual Creative Process. Creativity Research Journal, 24:4, 296-303. Yunlu, D. G., Clapp-Smith, R., \& Shaffer, M. (2017). Understanding the Role of Cultural Intelligence in Individual Creativity. Creativity Research Journal, 29(3), 236-243. 